\title{
Lived Experiences of Women Following a Stillbirth Delivery in Mityana Hospital
}

\author{
Kasule Ahmed ${ }^{1} \quad$ Josephine Namyalo $^{2}$ Caroline, Kambugu, Nabasirye ${ }^{3}$ \\ Patience Nakalega $^{4}$ Jacqueline Kobusingye ${ }^{5}$ \\ 1.White Ribbon Alliance Uganda, P.O Box 10663, Kampala, Uganda \\ 2.Faculty of Public Health, Nursing and Midwifery, Uganda Christian University Mukono, P.O box 4, Uganda \\ 3.Faculty of Health Sciences, Department of Nursing and Midwifery, Lira University, P.O Box, 1035, Uganda \\ 4.Faculty of Public Health, Nursing and Midwifery, Victoria University, Kampala, P.O Box 30866, Uganda \\ 5.Faculty of Public Health, Nursing and Midwifery, Uganda Christian University Mukono, P. O Box 4, Uganda
}

\begin{abstract}
Background: The World Health Organization (WHO) defines a stillbirth as a baby born with no signs of life at or after 28 weeks' gestation. In high income countries, it is evident that a new-born will survive after 25 weeks' gestation, compared to 28-32 weeks' gestation in low resource countries. The global stillbirth rate is estimated to be 13.9 still births per 1000 total births. In Africa, the still birth rate is 10 times that of the developed countries, indicating 29 births Vs 3 per 1000 live births. This paper recounts women's experiences following the delivery of a Stillbirth. Materials and Methods: The study used a Phenomenological study design to describe the essence of the women's experiences following the delivery of a Stillbirth. The study focused on 16 women aged 17-35, who had experienced stillbirths both macerated and fresh, these were the primary sources of information for the study. The in-depth interviews held with participants revealed that the stillbirth Phenomenon has a major negative impact on the reproductive health lives of women and the magnitude of grief and the associated mysteries surrounding stillbirth make the whole experience unbearable. The paper looks at the short and long term experiences of birthing a silent baby and the different strategies used by women to cope with the experience. Findings: The Stillbirth Phenomenon has a major negative impact on the reproduction lives of women. The magnitude of grief and the associated mysteries surrounding stillbirth make the whole experience unbearable. Women experience untold grief from the loss, coping with the sad memory of loss for all their life and at time with little or no support. Conclusion: Although they always come up with self-coping mechanisms, there is a need to provide psychological and social support to these mothers who have experienced a still birth. The findings from this study show the physical, social and psychological challenges women endure during the occurrence of the stillbirth phenomenon. These findings can be used to inform efforts aimed at providing support to women who fall victim of stillbirth so as to make the experience less painful. The findings will also pave way for more research on experiences of women following Stillbirths events and other silent tragedies impacting maternal health in the country and the world at large.
\end{abstract}

Keywords: Stillbirth, Experiences, Grief, bereavement, Care and Support, Coping, phenomenology

DOI: $10.7176 / \mathrm{JHMN} / 92-04$

Publication date:August $31^{\text {st }} 2021$

\section{Introduction}

Stillbirths are among the less prioritized issues of public health concern which affects approximately 2.6 million families annually worldwide [1]. The death of an unborn child is a tragic event for mothers, fathers, siblings and the wider family. It presents itself with a baffling array of emotional distress where birth and death collide and mothers move from a trajectory of expectation to one of grief [2]. These emotions are made worse by the insensitive health system, health care providers, friends, and neighbors, as well as strained marital relationship and financial burdens [3]. In Uganda, the overall stillbirth rate remained at 21 per 1,000 deliveries in 2016/17 and the first half of 2017/18. The fresh stillbirth rate was slightly lower than in 2015/16:10.2 and 9.7 per 1,000 in 2016/17 and first half of 2017/18 respectively. Mityana district registered One of the highest numbers of stillbirth cases in 2016/2017 financial year; 96/1000 deliveries. (AHSPR 2017/2018) [4].

The loss of a child is recognized as a very difficult life experience which can often cause complicated grief reactions and negative effects on the psychological and physical well-being of women [5]. While they mourn a baby lost, they are also grieving for the future and expectations lost thus care and support are key for them. Several studies have looked into the bereavement resulting from stillbirth and the results have shown a range of emotions that women experience. Common emotions experienced by women following the diagnosis of a stillbirth include feelings of guilt and blame, regret, fear and grief [6], stigma and unsure of further pregnancies or parental future hopes [7]. The grief and other mysteries surrounding a stillbirth event have an impact to psychological, social interactions and economic abilities of women and their families [8]. It's important to note that the bond between mothers and their unborn babies is high thus a stillborn scenario is not one to forget thus much support is required to help them deal with the loss and cope with the experience. 
The limited awareness of stillbirth and little or no social recognition of a stillbirth loss negatively impacts on women's coping abilities since their loss cannot be openly acknowledged, publicly mourned, or socially supported thus left to battle with the disenfranchised grief [9]. A renewed global focus in 2016 on the prevalence of stillbirth and its associated impact sought to heighten public awareness of stillbirth as a societal issue; it proposed specific criterion for successful integration of stillbirths into post-2015 initiatives for women's and children's health [10]

Dealing with grief and the whole stillbirth experience is a highly an individual venture; there's no right or wrong way to grieve and all depends on many factors, including one's personality, the family and society he has, coping style, the general aspects surrounding the individual experience, and how significant the loss was to you [11]. Coming to terms with that grief and loss and learning to cope is a difficult process and victims always adapt different ways to cope with the experience. There are scanty studies looking at general experiences of women following a delivery of a stillborn in the Uganda context. Women's experiences following a stillbirth are influenced by different factors ranging from professional, social and economic aspects and these also influence their coping abilities.

The objective of this study was to explore and describe the impact of stillbirths on bereaved women and explore their varying coping strategies used to overcome the tragedy. Listening to the victimized women provided a clear understanding of the impact stillbirth thus providing evidence for interventional strategies. The results provide an understanding of the actual effects and challenges women face following a delivery of a stillborn and provide evidence for the need of developing and disseminating bereavement care/support guidelines for stillbirth victimized women in Uganda and the world at large.

The findings also provide more opportunities for much needed future studies around Stillbirth impacts to women, their families and the maternal health sector at large.

\section{Materials and Methods}

\section{Study Design and Setting}

A phenomenological study design was used for this study because it helps to understand complex social processes, to capture essential aspects of a phenomenon from the perspective of study participants. Interpretative phenomenological analysis is an approach to psychological qualitative research that aims at offering insights into how a given person, in a given context, makes sense of a given phenomenon [18, 19]. The regional referral hospital has a catchment population of over 165,717 people and it records some of the highest stillborn cases in the country, this provided motivation to conduct this research.

\section{Recruitment and Participants}

Sixteen mothers who had ever experienced a stillbirth in the last 12 months preceding the study were recruited to take part in the research. All women who experienced a stillbirth phenomenon were included in the study and we excluded mothers with mental health issues, the dumb, deaf, terminally ill women and those who were unable to narrate their experiences. The findings are based on in-depth interviews conducted among sixteen mothers who had experienced a still birth in.

\section{Data collection}

A purposive sampling technique was used to identify the participants to be interviewed. Participants were selected from the hospital's maternity registers and selection was based on the following aspects; A gap of four months from the occurrence of the event, Cases with fresh stillbirths, Cases with macerated stillbirths, Mothers who normally pushed the stillborn, Mothers who had to go for C-section procedure, Mother who had a stillborn during her teenage years, Mothers who had a stillborn on their first pregnancy, Mothers who had a stillborn on their other pregnancy other than the first. The in-depth interviews method of data collection was used. A one on one interview was held between the researcher and the participant with observations used to capture non-verbal messages and other important gestures made by the participant. An In-depth interview guide was used to explore the nature of experiences had by the participants after having a still birth. It included questions on how the participants knew they had got still birth, who supported them during the process, how they were affected by the experience, how they coped after getting the stillbirth. All the interviews were audio-recorded following permission from the research participants.

\section{Data analysis}

All the interviews were transcribed verbatim. The study used an Inductive thematic approach for data analysis. The first stage of the data analysis involved the repeated reading of all the interview transcripts and extracting significant statements, including quotes. The significant statements were coded, and the initial codes were then grouped into more abstract levels of themes.

\section{Ethical Approval}

Ethical approval was sought from Research Ethical Committee of Uganda Christian University and Mityana District Chief Administrative Officer and the District Health Officer. 


\section{RESULTS}

Following the data analysis the researchers discovered that the participants had feelings of grief and sense of loss, memories created after the stillbirth, questioned about the cause of the stillbirth and who to blame, thoughts of labor and delivery of a stillborn, and expectations of support following a stillbirth.

\section{Feelings of Grief and sense of Loss}

Grief from the loss of their unborn child was a common response that was reported by all participants. They expounded that it came to them as a shock and an unbelievable happening that was totally unbelievable. Women noted that this event gave them a lot of grief both in the short and in the long term and it's the sadness that will always be part of them because to stop the pain one has to forget yet it's had to forget such an event in someone's life. Grief and loss was experienced at the different levels in the following ways

$i$. From Anticipation and excitement for the baby; all the women expressed some sort of anticipation or excitement for the arrival of their baby. Women noted that they had a lot of joy watching the pregnancy grow and feeling their babies making movements. They were eager to meet their unborn children. This excitement was physically visible during the interview when the participants shared about the excitement of having a baby and the expectations they had for them. One of the women shared that;

"...every woman looks forward to meeting her child even if it's the 10th pregnancy, and for me it was the first pregnancy so I was excited to meet my child and it was sad that I met him dead..."

ii. From the loss of a child; Although the loss of an unborn baby may not register in the hearts of others, for mothers it does and the loss always comes as a shock for all the mothers, it gives them sadness, anxiety, anger and depression. One mother noted,

"... Of course the loss of my child gave a lot of pain and grief, and the fact that I didn't find out what really caused her death really hurts. I was anxious to have a baby after a few years of trying so I was careful with the pregnancy since day one so I really got hurt when I lost her..."

iii. From the mysteries associated with stillbirth; Instead of looking for baby clothes and toys for their babies, they were looking for coffins and making preparations for burial. This also incited a lot of grief for the women, each preparatory activity to send off their dead baby made them sad and grieved. One mother noted that;

"...the moment which had to be your best becomes the worst in your life because instead of buying pampers and other things to take care of your child you end up buying coffins to bury him, people who would be happy for you congratulating you are consoling you and feeling pity for you so it's always hard..."

iv. From the after birth healing process/period; Women reported that the healing process was another hard period for them especially those who had to deliver by Caesarean procedure. They informed that the pain and post natal services seemed meaningless because they had nothing to show for it and even though most of them were sad, they had to go through the whole process like any other woman who has delivered. One of the participants noted;

"...Even the healing process because like me who went for $C$-section the wound always reminds you of that incident, so the healing process also gave me a lot of sadness because I felt I was going through

\section{Memories created following stillbirth} this for nothing..."

Creating memories is another important aspect of the stillbirth experience because to some, it helps in validating parenthood and accelerating the healing process. Although not considered as an essential issue, memory creation was commonplace during the different interviews. Women made memories in the following aspects

$i$. Seeing and holding; this was the common memory creation event that most of the participants reported, they all informed that health workers asked them whether they wished to see and hold their babies. Some reported seeing but not holding and others were able to hold and spend some time with their children. Some mother seemed to have liked the idea seeing and holding their newborns even though it's another source of grief. One participant noted that;

"...The doctor asked me whether I wanted to see the baby, I saw him but not for long; he was very big and even though it makes me sad, I still remember how he looked"

Another mother said;

“...I did see the baby, I even held him for a while. He had grown, looked lovely... I felt happy but sad at the same time, I wished I could breast feed him at least once but I couldn't but at least holding him gave me some kind of relief and it helped me mourn him like he was born alive"

Some mothers didn't enjoy having visual memories of their dead children; they didn't want look at them or even touch them because they didn't want to have memories that would bring them sadness. One mother noted that;

“... he didn't look nice I even didn't want to look at him for a long time because I didn't want to have 
that memory of him, I only glanced at him but even though it was for seconds, that image still disturbed me up to now."

ii. Attending burial; A few of the participants reported that they were able to attend their babies burial and funeral and this was a way of paying respects to them and recognizing that they existed and died like another person. One of the participants who attended the burial noted;

"...were discharged the following day and we went for burial. She was buried nearby so I managed to attend her burial and pray for her like any other dead person..."

Mothers also had memories of support and care at the interpersonal and institutional levels. Memories mother had at the interpersonal level was the support given by family and friend in organizing burial and funerals for the unborn baby. One mother noted

"...I managed to sleep and when I woke up, my mother told me my husband with some friends had taken the body for burial"

Another mother noted that

"...my husband together with my brother handled everything from getting the body from the hospital to burial"

At the Institutional level, women appreciated the health workers efforts of making the experience a memorable one especially through professionally breaking the news to them and taking care of them until delivery time. One of the participants noted

"...they took care of me during delivery and the midwife who broke the news was caring, she was very kind to me and spent almost an hour trying to console me..."

Another mother noted;

$$
\begin{aligned}
& \text { "...health workers did their job especially after we found out that the baby had died, they } \\
& \text { consoled me, explained to me what was to be done next..." }
\end{aligned}
$$

Apart from a few who had personal relationships with health workers, women reported negative feelings about the level of care after delivery. They informed that they didn't receive satisfying care when they were out of the labour suit and they didn't get any special care but same post-natal care services like any other women who had a live baby.

“...health workers didn't really care much especially after delivery, I think I felt their care when I was in the labor suit but before and after it wasn't much..."

Another mother noted;

"...Even at the hospital the health workers took care of me especially during delivery though I feel they should also take care of women after delivery because at this time we are in pain and shock and we need to have them take care of us more than they do..."

Similarly, at community level women had positive memories, they appreciated the level of concern that their neighbors and other community members took in handling burial/funeral services and consoling them. One mother noted;

“...neighbors really helped me a lot. I used to have more than five people check on me each day and giving courage to move on..."

\section{Thoughts about the cause and who to blame}

From the interviews, it was clear that women usually don't get to know the actual cause of the stillbirth when it happens since it's not always easy to know the cause immediately thus some decide to blame themselves or others

Cause and blame were looked at in two different aspects. One was blame on self; mothers blaming themselves for the death of their children and blame on others; mothers putting the blame on other persons or determinants

i. Blame on self, Most of the participants didn't blame themselves for the event, they felt they took the required necessary steps and measures to ensure safety of their unborn children and the entire pregnancy period. One mother noted

"...I took all the necessary precautions because am that kind of a person who wants to do things right so I really don't know what happened to my child because I was health..."

Another mother noted;

"I also encouraged myself that it was God's decision and not even me could save my child so I had to let go"

Only one mothers blamed herself for the loss of her child, she felt that she didn't go to the hospital in time,

"... at times I think It was my fault because maybe if I came to the hospital at the time of the bleeding maybe he was still alive and something would have been done so that's also disturbs my mind at times.." she noted

ii. Blame on other; some of the participants in the study blamed health workers for reluctance that might have resulted into the death of their children. They felt that if health workers were highly responsive, they would have saved the babies. One mother noted that; 
“...I used to tell them how I felt they would have done something about it but they only kept on asking me how I felt and I told them but they were not responsible enough and didn't take good care of me at that time but instead took much care when I was delivering the baby... and I think they sensed it but they didn't mind about it; my child had grown maybe I would have delivered him earlier..."

Other mothers didn't attach any blame on self or any other person and chose to believe that maybe it was meant to happen, they chose to believe that it was God's plans and there was nothing to be done to save their unborn babies

\section{"...I couldn't blame anyone because I did what I had to do to have a safe pregnancy and the health} workers also tried their best so I had to accept that this was meant to happen."

At the Interpersonal level, one of the participant reported being blamed by her husband and her in-laws for the death of the baby. She noted;

“... my in-laws and some of my family members with my husband all blamed me for her death, of course some didn't tell me directly but I could feel when talking to them and also could hear it through rumors ..."

Other blame concerns were reported by another mother, she noted;

"...Even my husband; even though he blamed me for choosing the clinic, he was there for me because he knew I wouldn't what to see my child..."

Most of the mothers didn't report being blamed for the death of the child as their family members were supportive all through the situation

At Institutional level; No participant reported being blamed for the death of their children by the health workers. Most of them were concerned about not knowing what could have led to the death of their children and the fact that health workers couldn't tell at that very moment made the situation hard for them. One mother noted;

"... Of course the loss of my child gave a lot of pain and grief, and the fact that I didn't find out what really caused her death from the health workers made it worse..."

Another mother said that

“... Even the doctors couldn't tell what could have been the problem and up to now we didn't find out the exact cause of death because as far as I know, I was health all through my pregnancy period..."

One of the participant felt that the health workers could have done more and maybe they would have saved her baby but kept on sending her for scans. She noted;

“...even hate the general hospital. They didn't show responsibility even though I explained to them how I felt immediately they administered that drug but they didn't mind, they had sensed that something wrong was happening but they never minded maybe because they wanted to save their colleague and put the blame on me..."

Community level, No aspects of cause and blame were reported at this level

\section{Labor and Delivery of a stillborn}

Labor and delivery was also another trying period for the mothers, many were unsure whether they would manage to deliver their babies with the sadness in their hearts. Most of the participants in the study had normal delivery, they managed to recollect themselves emotionally to go through the birth experience and the ones who failed were recommended to have a $\mathrm{C}$-section.

Women reported their experiences during labour and delivery in the following ways;

"...emotionally I was weak and still in shock, I didn't even know how I was going to be able to push the baby out but eventually at around 5pm, I managed to push the baby out, it was a girl and she looked fine only that she wasn't breathing...” one of the mothers noted

Another mother noted;

"... amidst all the anxiety and sadness, I delivered normally after sometime..."

Some women wanted to push but failed, one mother explained that

"...I wanted to push my child out, I fear C-section and dislike them but I failed because I was already weak I think, even with the help of the inducing drugs I could manage, we tried but later the doctor decided that I go for a C-section because it was getting risky..."

Some of the mothers couldn't push under the circumstances they found themselves in and were forced to go for a $\mathrm{C}$-section. One mother noted;

"...Another thing that hurts me is going through the C-section, I never wanted C-sections and going through it for a dead baby tortured me psychologically and it doubles the grief from the loss of my baby..."

Another Mother noted

"...I was taken to the labor suit and tried to push out the baby but I failed...the doctor told me if we delay the worst could happen, we agreed to go for a C-section which they did and took out the baby..." One of the participants had to undergo a C-section as already advised during her ANC and when this happened, it was another reason that necessitated the procedure. One of the participants noted; 
“...I was already going for a C-section; it was recommended for me during my ANC visits so I had made preparations with a doctor to take care of me when the time came..."

Interpersonal level; only one participant reported support from family and friends during labour and delivery; one mother noted that;

“...my sister was there during delivery and encouraged me to push; she even helped in handling and dressing the baby with the health workers..."

Institutional level; despite the grief from losing the baby, most women appreciated the level of care given to them by the health workers during this period. One of the participants noted that;

"...the health workers took care of me because I was different; among all the people who were in the labor suit, nobody was allowed to have an attendant but I had two attendants and the health worker was always asking me how I felt and done frequent checkups on me until I delivered, they also kept on encouraging me not to be sacred and always said kind words..."

Another mother said;

"... The health workers did they part I think, like any other pregnant women, they took care of me during delivery and the midwife who broke the news was caring..."

Most participants also noted that doctors took time and explained procedures that were going to be used to remove the baby. Many women managed to push their babies out. One mother noted that;

"...he (the doctor) told me we needed to take him out and that I was going to deliver normally, he had some tablets which he said will help me to push..."

\section{Expectations of support by mothers following a stillbirth}

At the individual level, Participants noted that the event comes along with specific needs but the common need identified by the majority was care and support during the event at all levels. They argued that emotional and psychological support is paramount at this level and that it's essential for both the short and long term healing. Care and support from people especially family members is very helpful and it was essential for them in healing process. One mother noted that she liked being around people so that she doesn't have to think a lot;

“...needed to stay with people and be able to talk so that I don't drown up in thoughts, my family and some few friends always came around to console me and I liked it...”

Another mother noted that

"... you heal first when you have family and friends around you during challenging times and for me it was no different, I needed people to make me strong and help me heal fast..."

Some of the participants were not comfortable interacting with people because they didn't want to be pitied all the time. They needed to avoid people so that they can fight on their own. One of the mothers noted;

“...was also hard to be around the community people because everyone feeling for you, everywhere you pass people gives you that pitiful eye and this only made me uncomfortable..."

Institutional level, women needed professional care and support from health workers and even though all of them agreed that they got it before delivery and during delivery, they were not able to get it after delivery yet they equally needed it. One mother noted

“...our hospitals if you don't have enough money, the level of care is so little so I can't say I got enough support from the hospital maybe during delivery and immediately after, they tried comforting me but after that, it was my family, relatives and other close friends..."

Women also need to find out what really led to the stillborn but most of them didn't get conclusive answers from health workers. One mother noted;

“...doctor asked a few questions and later he told me the baby had died, he said it might be because he got tired..."

Another mother said,

"...Dr told me they will try finding out the cause of death when I asked and they were to contact me after sometime but they didn't and I also lost the interest of finding out..."

Coping strategies

Believing that it was God's plan and it had to happen that way, almost all the women mentioned that believing in God's plans and accepting that this was meant happen was important in their coping journeys. Some women felt that believing in God and assuring themselves that everything happens because according to God's plans helped in quickening the healing process

“...I was able to move on because I am a Muslim and in my faith we believe that death is decide by Allah (God) and not even the Doctors would have saved my child and I believe He (God) has a better plan for me"

Social interactions, to some mother's social interaction helped them in grieving. They noted that once you share your problems with others, it's a bigger step in solving that particular problem and the same goes with grief. One mother noted that,

"I needed to stay with people and be able to talk so that I don't drown up in thoughts, my family 
and some few friends always came around to console me and I liked it because I was able to draw strength from them"

Placing maternal love on other children, Mothers informed that paying more attention to other children either biological or relatives' children was also helpful. One mother informed that;

"I took care of my sister's two daughters. Occasionally, we could sit and watch television together and play together. This helped me forget my stillbirth pain. I also helped in preparing them for school daily and helped them with their homework"

Expectation of next pregnancy, all the participants noted that the idea of getting pregnant again helped them cope with situation. They knew they still had a chance to have other children and the thought of this calmed them down. Many women said that they wanted to get pregnant again and give birth to a healthy baby. They said that the anticipation of a normal delivery and a healthy baby keeps them going. One mother said that,

"...the pain was a lot but I looked forward to having another pregnancy, my husband always told me that we shall get another child and this always calmed me and made me strong until I got pregnant again"

\section{DISCUSSION}

The impact of stillbirth is far reaching for the victimized women and the experience has a lifetime impact on their lives thus it's critical to have a positive one amidst their sorrows. The grief from the loss of their unborn baby may not be legitimized by many but to the women themselves, they will hold that loss at heart and remember everything pertaining that experience. The experiences of parents in this study add an in-depth insight into the experience of stillbirth and the general perinatal grief that is valuable in understanding the impact that a stillbirth phenomenon has on women and their families. [20, 21]

The results from this study showed that grief was the most pressing issue following a stillbirth. Although a normal, feeling of grief and associated symptoms can persist for many years and deter normal health wellbeing of women. Disenfranchised grief, which was common in this study and other studies highly influences the coping ability of women thus it should be an issue of concern; awareness around stillbirth and support should be raised around stillbirth to enable communities identify with victimized women and act accordingly.

The kind of care and support accorded to women during the bereavement period is essential in shaping the general stillbirth experience. It is influenced by the attitudes and behavior of family members, hospital staff and the general community. Downe et.al (2013) [22] emphasized positive staff attitudes and behaviors for a positive experience; this is also the case with family members. It's important that family members and hospital staff not only understand the grief that women go through but also tolerate it and support them to cope with it. From the study, women echoed the importance of proper care and support following a stillbirth, they said that although nothing could be done to change the happening, the kind of support from health workers and family members can bring a difference in reducing the grief thus quickening the healing and coping process. The findings from the study show the urgent need of accelerating efforts towards the achievement of the goals set in the Every Newborn Action Plan. There is need for health workers to provide counseling and psychosocial support to mothers who have had such painful experiences during and after delivery.

\section{Strengths and limitations}

The strengths of this study is it explores the impact of stillbirths and coping mechanisms of mothers who have gone through the experiences using qualitative methods. The major limitation of this study is that these experiences are particular to the interviewed participants and not generalizable in a wider context; however the insights and experiences are likely to have transferrable commonalities for other mothers in similar circumstances.

\section{Conclusion}

The psychological impact mothers get after suffering still births isn't prioritized by the health care system and health workers, which makes them remain with long lasting effects. The kind of care and support women receive following a stillbirth has a major influence on shaping their general experience and the impact the phenomenon has on the health of women both in the short and long run. It is important that families, communities, the health care system and health workers provide adequate and sensitive modes of care and support to the women all through the experience and enable them learn to live amicably with the event. These voices from this study are valuable evidence assets for policy formation and establishment of clear guidelines for bereavement care.

\section{Authors' Contributions}

KA and JK conceptualized the idea. JK supervised protocol writing and data collection. KA, JN and JK did the data analysis, interpreted the findings, participated in writing the first draft of the manuscript, CKN and PN revised the manuscript, and approved the final manuscript for submission. All authors read and approved the 
final manuscript.

\section{References}

1. Cousens S, Blencowe H, Stanton C, Chou D, Ahmed S, Steinhardt L, et.al. National, regional, and worldwide estimates of stillbirth rates in 2009 with trends since 1995: a systematic analysis. Lancet. 2011 Apr 16; 377 (9774): 1319-1330. DOI 10.1016/S0140-6736(10)62310-0.

2. Daniel N, Meaney S, Keelin O.(2018), The impact of stillbirth on bereaved parents: A qualitative study. ResearchGate. 2018 January; 13(1):e0191635. DOI: 10.1371/journal.pone.0191635.

3. Gopichandran, V., Subramaniam, S. \& Kalsingh, M.J (2018). Psycho-social impact of stillbirths on women and their families in Tamil Nadu, India: a qualitative study. BMC 2018 April 20; 109 (2018).

4. Anette K, Birgit W. Complicated grief after perinatal loss. Dialogues Clin Neurosci, 2012 Jun; 14(2): 187194. DOI: 10.31887/DCNS.2012.14.2/akersting

5. Downe S, Schmidt E, Kingdon C, Alexander E. Bereaved parents' experience of stillbirth in UK hospitals: a qualitative interview study. BMJ. 2013 Feb 14; 3(2): e002237. DOI:10.1136/bmjopen-2012-002237

6. Murphy S. Reclaiming a moral identity: stillbirth, stigma and 'moral mothers'. PubMed. 2012 Aug; 28(4):476-80. DOI: 10.1016/j.midw.2011.06.005.

7. HUTTI M. Social and professional support needs of families after perinatal loss. PubMed. 2005 Sep-Oct; 34(5):630-8. DOI: 10.1177/0884217505279998.

8. Samantha M, Cacciatore J. The psychological, social, and economic impact of stillbirth on families. Researchgate,net. 2017 February; 22(3). DOI: 10.1016/j.siny.2017.02.002.

9. Kenneth D J. Disenfranchised Grief. Lexington; Lexington Books; 1989

10. The Lancet. Ending preventable stillbirths. [INTERNET]. Available from: https://www.thelancet.com/series/ending-preventable-stillbirths (Accessed June 20, 2020)

11. Help Guide. Coping with Grief and Loss. [INTERNET]. Available from: https://www.helpguide.org/articles/grief/coping-with-grief-and-loss.htm. (Accessed June 21, 2020)

12. Cacciatore J. The unique experiences of women and their families after the death of a baby; Social Work in Health Care. PubMed. 2010; 49 (2):134-48. DOI: 10.1080/00981380903158078.

13. Cacciatore J, Schnebly S, Froen J. The effects of social support on maternal anxiety and depression after stillbirth; Health and Social Care in the Community. PubMed. 2009; Mar; 17(2):167-76. DOI: 10.1111/j.1365-2524.2008.00814.x.

14. Avelin P, Radestad I, Saflund K, Wredling R, Erlandsson K. Parental grief and relationships after the loss of a stillborn baby. PubMed. 2013 Jun; 29(6):668-73. DOI: 10.1016/j.midw.2012.06.007

15. Lehman, D.R., Ellard, J.H. and Wortman, C.B. Social Support for the Bereaved: Recipients' and Providers' Perspectives on What Is Helpful. Journal of Consulting and Clinical Psychology. 1989; 54(4), 438-446. https://doi.org/10.1037/0022-006X.54.4.438

16. Stroebe W., Stroebe M., Abakoumkin G. \& Schut H. The role of loneliness and social support in adjustment to loss: a test of attachment versus stress theory. PubMed. 1996 Jun; 70(6): 1241-9. DOI: 10.1037//00223514.70.6.1241.

17. WHO, UNICEF. 2014. Every Newborn: an action plan to end preventable deaths, Geneva: World Health Organization. [INTERNET]. Available via: https://www.who.int/docs/default-source/mcadocuments/advisory-groups/quality-of-care/every-new-born-action-plan-(enap).pdf?sfvrsn=4d7b389_2). (Accessed on June 28 2020)

18. Nuzum D, Meaney S, O’Donoghue K. The provision of spiritual and pastoral care following stillbirth in Ireland: a mixed methods study. BMJ. 2016 Jun; 6(2):194-200. DOI: 10.1136/bmjspcare-2013-000533.

19. Nuzum D, Meaney S, O’Donoghue K, Jackson M. Stillbirth and suffering in Ireland: a theological reflection from healthcare chaplaincy. Practical Theology. 2017 March 2; 10(2). doi.org/10.1080/1756073X.2017.1296062

20. Mills TA, Ricklesford C, Cooke A, Heazell AE, Whitworth M, Lavender T. Parents' experiences and expectations of care in pregnancy after stillbirth or neonatal death: a metasynthesis. PubMed. 2014 July; 121(8):943-50. doi: 10.1111/1471-0528.12656

21. Burden C, Bradley S, Storey C, Ellis A, Heazell AE, Downe S, et al. From grief, guilt pain and stigma to hope and pride - a systematic review and meta-analysis of mixed-method research of the psychosocial impact of stillbirth. BMC. 2016 January 16; 16: (9). doi: 10.1186/s12884-016-0800-8

22. Downe S, Schmidt E, Kingdon C, Heazell AE. Bereaved parents' experience of stillbirth in UK hospitals: a qualitative interview study. BMJ. 2013 February 14; 3(2), doi: 10.1136/bmjopen-2012-002237 